\title{
Evaluation of a micromethod gallery (API Staph) for the identification of staphylococci and micrococci
}

\author{
RR MARPLES, JF RICHARDSON \\ From the Division of Hospital Infection, Central Public Health Laboratory, Colindale Avenue, Colindale, \\ London NW9 $5 H T$
}

SUMMARY A collection of 300 well-characterised strains of staphylococci and micrococci was examined by a commercially available gallery micromethod (API Staph). The results were compared with biotyping by conventional methods. The gallery micromethod broadly agreed with the biotyping scheme used but gave an identification from the index supplied in less than $30 \%$ of the trials. Reproducibility was better after $48 \mathrm{~h}$ incubation than after $24 \mathrm{~h}$ but was poor for the tests for phosphatase and acetoin. When compared with the results of conventional tests, the tests for acetoin, phosphatase and urea were unsatisfactory.

Two schemes based mainly on simple biochemical tests have been widely used for the identification of coagulase-negative staphylococci. The first, described by Baird-Parker ${ }^{1}$ and later modified by him $^{2} 3$ and others, ${ }^{45}$ is based on the acidification of solid media containing a small number of "sugars", and the phosphatase and acetoin tests. The second, described by Schleifer, Kloos and co-workers, ${ }^{6-9}$ tests rather more "sugars" but employs different bases and incubation temperatures. This scheme was used as the basis of a micromethod identification gallery (API Staph) which is now widely available. ${ }^{10}$ In a study of the Micrococcaceae, Feltham ${ }^{11}$ included the API 50E and $20 \mathrm{E}$ galleries, but he did not use the API Staph gallery.

A collection of 300 well-characterised strains of staphylococci and micrococci available to us ${ }^{12}$ was used to assess the new gallery.

\section{Material and methods}

\section{SOURCE OF STRAINS}

The 300 strains were selected to include approximately one-third of named strains from culture collections, one-third of strains from newborn babies, schoolchildren and adults isolated in this Division and one-third of strains isolated elsewhere. ${ }^{13}$ As far as possible strains were selected to include 10 of each Baird-Parker biotype. The strains were lyophilised and working cultures kept at $-20^{\circ} \mathrm{C}$ in glycerol broth. The strains were subcultured onto nutrient agar, and incubated at $30^{\circ} \mathrm{C}$ for $24 \mathrm{~h}$.

\section{MICROMETHOD IDENTIFICATION GALLERY (API STAPH)}

The gallery consisted of 20 cupules containing substrates and appropriate indicators in a dried form. The order of the substrates was: negative control, glucose, fructose, mannose, maltose, lactose, trehalose, mannitol, xylitol, melibiose, nitrate, $\alpha$ naphthyl phosphate, pyruvate (for the production of acetoin), raffinose, xylose, sucrose, $\alpha$ methyl glucoside, $\mathrm{N}$ acetyl glucosamine, arginine and urea.

\section{INOCULATION PROCEDURE}

The procedure recommended by the manufacturers was followed. For each strain an ampoule of the suspending medium (modified from Brun et $a^{10}$ ) was opened. A small amount of growth from nutrient agar was picked up on the tip of a pasteur pipette and suspended in the ampoule by repeatedly taking medium into the pipette, to an opacity equivalent to tube 2 on the McFarland scale. The tube parts of the cupules were then carefully filled without bubbles. Only the cupules containing arginine and urea were sealed with sterile liquid paraffin. Each gallery was placed in a plastic incubation tray containing $5 \mathrm{ml}$ of water to maintain humidity, covered and incubated at $37^{\circ} \mathrm{C}$.

\section{RECORDING PROCEDURES}

Readings of the tests containing $\mathrm{pH}$ indicators were made after 24 and $48 \mathrm{~h}$ and reagents added to the 
cupules containing nitrate, $\alpha$ naphthyl phosphate and pyruvate after incubation for $48 \mathrm{~h}$.

For the nitrate test one drop of $0.8 \%$ sulphanilic acid in $5 \mathrm{~N}$ acetic acid and one drop of $0.6 \%$ naphthyl-1-amine in $5 \mathrm{~N}$ acetic acid were added. A red colour developing immediately was taken as a positive test.

For the phosphatase test one drop of reagent $A$ (trishydroxymethyl) aminomethane $250 \mathrm{~g} ; \mathrm{HCl}$ $(37 \%) 110 \mathrm{~g}$ : lauryl sulphate $100 \mathrm{~g}$, distilled water to one litre and one drop of reagent B (fast blue BB $3.5 \mathrm{~g}, 2$ methoxyethanol to one litre) were added to the $\alpha$ naphthyl phosphate cupule. A violet colour developing after $10 \mathrm{~min}$ was taken as a positive test.

To the pyruvate cupule were added single drops of $40 \% \mathrm{KOH}$ and of $6 \% \alpha$ naphthol in ethanol. A red colour developing after $10 \mathrm{~min}$ was taken as a positive test. Strains showing anomalous results were inoculated into two galleries and reagents added at $24 \mathrm{~h}$ to one while the other was treated as before.

Four months later the glycerol broth suspensions were resubcultured and all 300 strains were retested in the same way.

In order to identify the organism from the index supplied by the manufacturer the results were expressed as a numerical code. The tests in order along the gallery were divided into six groups of three tests and a final group of two tests. A positive reaction in the first position in a group was given value 1 , in the second position, 2 , and in the third position, 4. The sum of these values within each group made up one digit of the seven figure code numbers. The index listed the codes in numerical order and indicated the appropriate species name.

The results were also tabulated according to the biotyping scheme of Marples. ${ }^{12}$ This scheme is a modification of the scheme of Baird-Parker but is based on studies of the present strains by conventional methods.

\section{CONVENTIONAL METHODS}

The conventional methods used to characterise the strains were those of Baird-Parker ${ }^{1}$ (method A), those of Kloos and co-workers ${ }^{6-9}$ (method B) or the standard methods, usually those of Cowan and Steel. ${ }^{14}$ Acid production from arabinose, fructose, lactose, maltose, mannitol, ribose, sucrose, trehalose, xylitol and xylose was sought by both methods $A$ and B. In addition, acidification of cellobiose, fucose, galactose, mannose, melezitose, raffinose, salicin and turanose was tested by method A only. Reduction of nitrate was tested by methods $A$ and $B$ and method 1 of Cowan. Acetoin was sought by methods A and B. Phosphatase production was assessed by methods $A$ and $B$ and by the method of Pennock and Huddy. ${ }^{15}$ Arginine hydrolysis was tested by method A,
Møller's method and by incubation of arginine broth for 24 h. ${ }^{14}$ Method B was employed for the erythromycin-glycerol test, thioglycollate broth, and for resistance to lysozyme and lysostaphin. A variety of other tests including coagulase, gelatinase, urease, nuclease, splitting of Tweens and the egg yolk reaction were performed by standard methods.

\section{ANALYSIS OF RESULTS}

The reproducibility of the micromethod gallery was assessed by comparing the results recorded at 24 and $48 \mathrm{~h}$ incubation when tested on the two occasions. They were compared with the results of conventional tests, taking the results of method A where different methods gave conflicting results as these seemed the more sensitive. ${ }^{12}$ Much of the analysis had necessarily to be restricted to biotypes of Staphylococcus spp as the micromethod was not designed for Microccocus spp.

\section{Results}

IDENTIFICATION BY CONVENTIONAL

METHODS

On the results of the relevant conventional tests all strains were identified by both identification schemes. Then the strains were reclassified on all the results to form a new extension of the scheme of BairdParker in which the major divisions were subdivided to define more than 46 biotypes. ${ }^{12}$ The correlation of the three schemes for the staphylococcal biotypes is shown in Table 1 . In the Table the number of strains allocated to the new biotypes are listed and within each biotype the numbers and biotype of strains identified by the other two schemes are shown. As the identifications were very strictly made according to the published tables a few individual strains were probably misidentified. Single appearances of a different biotype have therefore been omitted from the Table.

It is evident from the Table that there was good agreement between the three schemes for some biotypes. The subdivisions of SI, SII and SIII showed a good correlation. There was relatively poor agreement over strains allocated to the subdivisions of SIV and SV and several anomalies in the subdivisions of the biotypes of SVI and M3 that were novobiocin sensitive though M3 $\mathrm{g}$ and $S$ capitis seemed identical. The saprophyticus species group (SVc, M3 a, b and $\mathrm{MXa}, \mathrm{b})$ and the xylosus species group correlated well.

RESULTS OF THE MICROMETHOD

The instructions for reading the gallery suggested that the glucose cupule be examined for acidification at $24 \mathrm{~h}$ and incubation continued to $48 \mathrm{~h}$ only in the 
Table 1 Correlation between biotyping systems for staphylococcal strains

\begin{tabular}{|c|c|c|c|c|c|}
\hline \multirow{3}{*}{$\begin{array}{l}\text { No of strains } \\
20 \\
8\end{array}$} & \multirow{2}{*}{$\begin{array}{l}\text { Marples biotype }{ }^{12} \\
\text { Sla }\end{array}$} & \multicolumn{2}{|c|}{$\begin{array}{l}\text { Baird-Parker biotype }{ }^{15} \text { and No of strains in that } \\
\text { biotype }\end{array}$} & \multicolumn{2}{|c|}{$\begin{array}{l}\text { Schleifer and Kloos species }{ }^{9} \text { and No of strains it } \\
\text { that species }\end{array}$} \\
\hline & & S1 & 19 & $S$ aureus & 19 \\
\hline & SIb & $\mathrm{S} 1$ & 8 & $S \mathrm{sp}$ & 8 \\
\hline 23 & SIIa & SII & 23 & $S$ epidermidis & 23 \\
\hline 8 & SIIb & SII lac- & 8 & $S$ epidermidis & 8 \\
\hline 6 & SIIc & SV & 5 & $S$ hominis $3 ;$ S epidermidis & 3 \\
\hline 13 & SIIIa & SIII mal ${ }^{+}$ & 13 & $S$ simulans & 13 \\
\hline 12 & SIIIb & SIII & 11 & $S$ simulans & 12 \\
\hline 6 & SIIIc & $\mathrm{S} \mathrm{sp}$ & 5 & $S$ simulans & 6 \\
\hline 9 & SiVa & S1V $7 ; \mathbf{M} 1$ & 2 & $S$ warneri $6 ; S$ hominis & 3 \\
\hline 9 & SiVb & M1 $6 ; \mathrm{S} 1 \mathrm{~V}$ & 3 & $S$ hominis $6 ; S$ warneri & 2 \\
\hline 4 & SiVc & S1V 2; M1 & 2 & $S$ haemolyticus & 4 \\
\hline 4 & SVaa & M2 & 3 & $S$ haemolyticus 2 ; $S$ hominis & 2 \\
\hline 7 & SVab & SV & 5 & $S$ hominis & 6 \\
\hline 2 & $\mathrm{SVb}$ & M2 & 2 & $S$ haemolyticus & 2 \\
\hline 3 & SVd & SV & 3 & Shaemolyticus & 3 \\
\hline 3 & $\mathrm{SVe}$ & S sp 1; SII 1; SV & 1 & $S$ hominis & 2 \\
\hline 6 & SV1a & SV1 (1) 4; SV1 (2) & 2 & S haemolyticus & 6 \\
\hline 3 & SV1b & SV1 (2) & 2 & $\begin{array}{l}S \text { warneri } 1 ; S \text { capitis } 1 ; \\
\quad S \text { haemolyticus }\end{array}$ & 1 \\
\hline 8 & SV1c & SV1 (1) 5; M3 (1) & 2 & $S$ haemolyticus $6 ; S$ warneri & 2 \\
\hline 13 & SV1d & SV1 (2) & 11 & $S$ warneri $11 ;$ S haemolyticus & 2 \\
\hline 2 & SV1e & SY & 2 & $S$ cohnii & 2 \\
\hline 6 & $\mathrm{M} 3 \mathrm{c}$ & M3 (2) & 6 & S haemolyticus 3 ; $S$ hominis & 2 \\
\hline 4 & M3e & SV1 (1) & 4 & S haemolyticus & 4 \\
\hline 4 & M3f & SV1 (2) & 2 & S haemolyticus & 4 \\
\hline 11 & M3g & M3 (3) 7; SV1 (3) & 4 & $S$ capitis & 11 \\
\hline 4 & M3h & SV1 (3) 2; M3 (3) & 2 & $S$ capitis $2 ; S$ haemolyticus & 2 \\
\hline 3 & $\mathrm{SVc}$ & M2 & 3 & $S$ saprophyticus & 3 \\
\hline 13 & M3a & M3 (1) & 12 & S saprophyticus & 13 \\
\hline 5 & M3b & M3 (2) & 5 & $S$ saprophyticus & 4 \\
\hline 2 & MXa & MX & 2 & $S$ cohnii & 2 \\
\hline 14 & $\mathrm{MXb}$ & $\mathrm{MX}$ & 14 & $S$ cohnii & 14 \\
\hline 6 & $\mathrm{M} 5 \mathrm{a}+\mathrm{b}$ & M5 & 6 & $S$ xylosus & 6 \\
\hline 10 & $\mathrm{M} 6 \mathrm{a}+\mathrm{b}$ & M6 & 10 & S xylosus & 10 \\
\hline
\end{tabular}

absence of such acid production. All but three of the 251 strains of staphylococci produced acid from glucose within $24 \mathrm{~h}$ and all by $48 \mathrm{~h}$, but 45 of the 98 tests on the 49 strains of micrococci remained negative at $48 \mathrm{~h}$ and in 15 trials all tests were negative. The micrococcal strains were not considered further.

\section{MICROMETHOD RESULTS RELATED TO BIOTY PE}

Table 2 shows the results of each of the 19 tests for each of the staphylococcal biotypes after incubation for $48 \mathrm{~h}$. Each strain was tested twice and the result was recorded as positive if more than $80 \%$ of the tests were positive, negative if more than $80 \%$ of the tests were negative and variable if the number of positive tests lay between $20 \%$ and $80 \%$. This procedure was selected because of the small number of strains in some biotypes and because of the problems of reproducibility which are discussed later.

The results with the micromethod gallery largely confirmed the biotyping system. This was not surprising as the biotypes were defined in terms of some of the same tests, though carried out by conventional methods. The biotypes of SII were defined on lactose negativity for SII $b$ and phosphatase negativity for SII c. These were distinguished by the micromethod. The biotypes of SIII were defined on maltose positivity for SIII a and mannitol positivity for SIII c. These differences showed in the micromethod results but some anomalies were evident, for example SIII was defined as acetoin-negative but gave variable results with the micromethod. The greatest numbers of variable results were seen in the biotypes of warneri-hominis species group (SIV and $\mathrm{SV}$ ) and in the haemolyticus-capitis group (SVI and M3 c-h). These are the least well defined in both classifications but within the biotypes some, such as M3 g ( $S$ capitis), were reasonably characterised.

The saprophyticus-cohnii species group (M3 ab, $\mathrm{Mx}$ and SV c) strains were well characterised by the micromethod and the variable positive results with xylitol could be expected. However, strains of $\mathbf{M x}$ ( $S$ cohnii), defined as phosphatase-positive, were variable by the micromethod. 
Strains of the xylosus species group (M5 and M6), defined as acetoin-negative were positive in the majority of micromethod trials, but the acidification of xylose was confirmed.

\section{IDENTIFICATION FROM THE INDEX}

After $24 \mathrm{~h}, 93(18.5 \%)$ of 502 tests gave an acceptable identification from the index rising to $137(27 \cdot 5 \%)$ using the $48 \mathrm{~h}$ results. Only 10 strains were clearly misidentified at $24 \mathrm{~h}$, in seven trials this was an identification as $S$ capitis of strains that later acidified additional substrates. The $48 \mathrm{~h}$ results misidentified one strain of $S$ epidermidis (SII) as $S$ aureus and one strain of biotype SV ab as S saprophyticus each on one occasion. The improvement in identification from the index using the $48 \mathrm{~h}$ results extended over all biotypes with the exception of $S$ capitis and $S$ saprophyticus where sucrose and xylitol respectively were not included as positive in the listed codes. Biotypes that were reasonably identified were restricted to $S$ aureus, $S$ epidermidis (SII a), $S$ capitis (M3 $\mathrm{g}$ ) and $S$ saprophyticus (M3 a) but it was clear that the index could be extended to improve identification if needed.

\section{REPRODUCIBILITY}

The results of the 16 tests read at $24 \mathrm{~h}$ on each time of testing were compared, a total of 251 comparisons for each test. Discrepancies of greater than $5 \%$ were found in the results for mannose, maltose, mannitol, $\mathrm{N}$-acetyl glucosamine, arginine and urea. Only urea gave more than $10 \%$ discrepancies in the two results. Reproducibility was excellent $(<1 \%$ discrepancies) for glucose, fructose, raffinose, xylose, and $\alpha$ methyl glucoside.

The results of all 19 tests could only be compared at $48 \mathrm{~h}$ since reagents for nitrate, phosphatase and acetoin were added to the majority of the galleries at that time. More than $5 \%$ discrepancies were found in the results for mannose, phosphatase, acetoin, $\mathrm{N}$ acetyl glucosamine and arginine. Reproducibility of the phosphatase test was least with 49 of 251 $(19.5 \%)$ results discordant and acetoin was little better with $10.8 \%$ of the results discordant. Reproducibility was improved at $48 \mathrm{~h}$ over the $24 \mathrm{~h}$ results for maltose, mannitol and urea but worsened for mannose. As with the $24 \mathrm{~h}$ results, excellent reproducibility was found for glucose, fructose, raffinose, xylose and $\alpha$ methyl glucoside.

\section{COMPARISON OF THE MICROMETHODS WITH CONVENTIONAL TESTS}

Only 17 of the 19 tests could be compared with conventional tests, usually to the method of BairdParker. ${ }^{1}$ If the micromethod gave a positive result but the conventional method gave a negative result the comparison was deemed a "false-positive" and the reverse "false-negative" (Table 3). More than $5 \%$ false-positives were found in the results of mannose, maltose, phosphatase and acetoin. The acetoin test gave the greatest number of falsepositives with 75 of the 502 tests $(14.9 \%)$ discordant. False-negative results in greater than $5 \%$ of the comparisons were recorded for phosphatase and urea. Urea was falsely recorded as negative in $\mathbf{5 7}$ of the 502 tests $(11.4 \%)$. Good comparability ( $<1 \%$ of the tests false) was seen in tests for glucose, fructose, raffinose and xylose. The test for the reduction of nitrate showed a number of false-negative results at the first replication of the study. Repeat testing showed that reduction past nitrate had occurred. For repeat testing and the second replication zinc dust was added with a wooden applicator stick to each apparently negative nitrate test and the result recorded as negative only if nitrate was reduced by the zinc and the colour developed. This confirmatory step was sometimes necessary even after only $24 \mathrm{~h}$ incubation.

It was possible to examine the frequency of "latepositives" at the same time where the micromethod gave a negative result at $24 \mathrm{~h}$ but a positive result at $48 \mathrm{~h}$ and the conventional method was positive. More than $5 \%$ of late-positives were seen for mannose, maltose, mannitol, arginine and urea. In 86 $(17 \cdot 1 \%)$ of the urea tests a correct positive was delayed.

\section{Discussion}

The classification of the staphylococci and micrococci remains a matter of controversy but a consensus appears to be evolving. The schemes of Baird-Parker ${ }^{1}$ and Kloos and co-workers ${ }^{7-9}$ do show some correlation of biotypes. ${ }^{5}$ Present schemes, particularly that of Marples $^{12}$ may be subdividing true species into biotypes that have epidemiological but not taxonomic validity. The reversal of the "splitting" movement has created the concept of species group ${ }^{16}$ and this trend may continue. It therefore becomes necessary to review the reasons for identifying species and biotypes of staphylococci and to consider the value of a convenient micromethod gallery in medical microbiology.

The main reason for identification of staphylococci from clinical sources is to separate $S$ aureus, a frequent pathogen, from the other less pathogenic species. At a higher level the identification of $S$ epidermidis and $S$ saprophyticus may define clinical syndromes. While $S$ epidermidis is the commonest coagulase-negative staphylococcus species associated with hospital-acquired infection ${ }^{17} S$ saprophyticus is frequently associated with urinary tract infection in 
Table 2 Results of API Staph on strains of different biotypes after incubation for $48 h$

\begin{tabular}{|c|c|c|c|c|c|c|c|c|c|c|c|}
\hline & & No of tests & Glucose & Fructose & Mannose & Maltose & Lactose & Trehalose & Mannitol & Xylitol & Melib \\
\hline \multirow[t]{2}{*}{ SI } & $\mathbf{a}$ & 39 & + & + & + & + & + & + & + & - & - \\
\hline & b & 16 & + & + & + & + & + & + & V & - & - \\
\hline \multirow[t]{3}{*}{ SII } & $\mathbf{a}$ & 44 & + & + & V & + & + & - & - & - & - \\
\hline & b & 16 & + & + & V & + & - & - & - & - & - \\
\hline & c & 12 & + & + & - & + & + & - & - & - & - \\
\hline \multirow[t]{3}{*}{ SIII } & $\mathbf{a}$ & 26 & + & + & + & + & + & + & - & - & - \\
\hline & b & 24 & + & + & V & - & + & + & - & - & - \\
\hline & $\mathrm{c}$ & 12 & + & + & V & - & 4 & + & + & - & - \\
\hline \multirow[t]{3}{*}{ SIV } & $\mathbf{a}$ & 18 & + & + & V & + & - & + & - & - & - \\
\hline & b & 18 & $-\psi$ & + & V & + & - & + & - & - & - \\
\hline & c & 8 & + & - & - & + & - & + & V & - & - \\
\hline \multirow[t]{5}{*}{ SV } & $\mathbf{a a}$ & 8 & + & $t$ & V & + & + & + & - & - & - \\
\hline & $a b$ & 14 & + & + & - & + & V & + & - & - & - \\
\hline & $\mathrm{b}$ & 4 & + & + & - & + & + & + & - & - & - \\
\hline & d & 6 & + & - & - & + & $i$ & + & - & - & - \\
\hline & e & 6 & + & + & + & + & + & + & - & - & - \\
\hline \multirow[t]{5}{*}{ SVI } & $\mathbf{a}$ & 12 & + & + & V & + & V & V & V & - & - \\
\hline & b & 6 & $\therefore$ & V & $V$ & + & - & - & $\therefore$ & - & - \\
\hline & c & 16 & + & + & V & + & + & + & + & - & - \\
\hline & d & 26 & + & + & V & + & - & + & + & - & - \\
\hline & e & 4 & + & + & t & + & + & $\rightarrow$ & $\cdots$ & - & - \\
\hline \multirow[t]{5}{*}{ M3 } & c & 12 & 4 & + & - & + & - & + & $:$ & - & - \\
\hline & e & 8 & + & - & - & + & + & + & : & - & - \\
\hline & f & 8 & + & - & - & + & - & + & 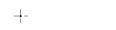 & - & - \\
\hline & $\mathbf{g}$ & 22 & + & + & + & - & - & - & V & - & - \\
\hline & $\mathrm{h}$ & 8 & - & + & - & - & - & + & 4 & - & - \\
\hline SV & c & 6 & + & + & - & + & + & + & - & V & - \\
\hline \multirow[t]{2}{*}{ M3 } & $\mathbf{a}$ & 26 & + & t & - & + & + & + & $\therefore$ & V & - \\
\hline & b & 10 & 4 & + & - & + & - & + & $\because$ & V & - \\
\hline \multirow[t]{2}{*}{$M x$} & $\mathbf{a}$ & 4 & + & + & $\uparrow$ & + & + & + & + & V & - \\
\hline & b & 28 & + & + & - & + & - & + & 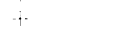 & v & - \\
\hline \multirow[t]{2}{*}{ M5 } & $\mathrm{a}$ & 6 & . & $\cdots$ & + & + & + & + & . & - & - \\
\hline & b & 6 & + & .. & t & + & V & + & + & - & - \\
\hline \multirow[t]{2}{*}{ M6 } & $\mathrm{a}$ & 16 & $t$ & $\therefore$ & t & + & + & + & t. & - & - \\
\hline & b & 4 & 4 & + & t & + & V & $\div$ & $!$ & - & - \\
\hline
\end{tabular}

$+>80 \%$ of the tests positive; $-<20 \%$ of the tests positive.

$\mathrm{V} 20-80 \%$ of the tests positive.

Table 3 Comparison of API Staph with conventional tests

\begin{tabular}{llll}
\hline Test & \multicolumn{3}{l}{ Percentage of 502 tests classified as } \\
\cline { 2 - 4 } & False-negative & False-positive & Late-positive \\
\hline Glucose & 0 & 0 & 0 \\
Fructose & 0 & 0.4 & 0 \\
Mannose & 2.0 & 8.6 & 5.4 \\
Maltose & 0.6 & 6.0 & $5 \cdot 2$ \\
Lactose & 0.6 & 2.4 & 4.6 \\
Trehalose & 0.2 & 1.8 & 2.6 \\
Mannitol & 3.4 & 1.8 & $7 \cdot 2$ \\
Xylitol & 1.4 & 4.6 & 1.6 \\
Nitrate & 1.6 & 1.4 & $\mathrm{NA}$ \\
Phosphatase & 6.6 & 12.0 & $\mathrm{NA}$ \\
Acetoin & 3.8 & 14.9 & $\mathrm{NA}$ \\
Raffinose & 0.4 & 0.6 & 0 \\
Xylose & 0 & 0.2 & 0.6 \\
Sucrose & 0.6 & 3.8 & 4.6 \\
Arginine & 3.6 & 3.4 & 7.6 \\
Urea & 11.4 & 0.6 & 17.1 \\
\hline
\end{tabular}

NA $=$ Not applicable. young women. ${ }^{1819}$ Other species may cause infection or have to be distinguished from the three most important species but usually do not need to be identified taxonomically. ${ }^{20}$

Biotyping implies an epidemiological purpose: to distinguish between closely allied organisms in order to determine the likely cause of infection or course of an epidemic. Like all typing schemes typability, reproducibility and discrimination become characters to be examined. Once the three common species are defined biotyping may subdivide the groups and, by including biotypes of the less frequent species, can be helpful in all infections caused by staphylococci. Other typing methods such as phage typing also may be helpful in epidemiological studies.

The micromethod gallery (API Staph) offers many advantages in that the results can be recorded as a code for epidemiological purposes, and by using an index, a taxonomic identification can be reached. 


\begin{tabular}{|c|c|c|c|c|c|c|c|c|c|}
\hline litrate & Phosphatase & Acetoin & Raffinose & Xylose & Sucrose & a methylglucoside & $N$ acetylglucosamine & Arginine & Urea \\
\hline & + & + & $\overline{-}$ & $\overline{-}$ & + & - & + & + & $\begin{array}{l}\mathbf{v} \\
+\end{array}$ \\
\hline & + & + & - & - & + & - & - & + & + \\
\hline & $\stackrel{+}{-}$ & $\stackrel{+}{+}$ & $\overline{-}$ & $\overline{-}$ & $\stackrel{+}{+}$ & $\overline{-}$ & $\overline{-}$ & $\stackrel{+}{v}$ & $\stackrel{+}{+}$ \\
\hline & + & $\mathbf{v}$ & - & - & + & - & + & + & + \\
\hline & v & $\begin{array}{l}\mathbf{v} \\
+\end{array}$ & z & - & + & $\overline{-}$ & + & + & + \\
\hline & & & & & & & & $v$ & \\
\hline & $\mathbf{v}$ & + & - & - & + & - & $\mathbf{v}$ & + & $\mathbf{v}$ \\
\hline & $\overline{\mathrm{v}}$ & $\mathbf{v}$ & $=$ & - & + & $\overline{-}$ & $\mathbf{v}$ & - & $\mathrm{v}$ \\
\hline & $\mathrm{v}$ & + & - & - & $\begin{array}{l}t \\
+ \\
-1\end{array}$ & $\bar{v}$ & $\begin{array}{l}\mathbf{v} \\
\mathrm{v}\end{array}$ & $\begin{array}{l}v \\
+\end{array}$ & $\overline{\mathrm{v}}$ \\
\hline & $\mathbf{v}$ & $\mathbf{v}$ & - & - & $t$ & - & $\mathrm{v}$ & $\mathrm{v}^{+}$ & $\begin{array}{lll}\mathrm{v} \\
\mathrm{v}\end{array}$ \\
\hline & $\mathrm{v}$ & + & - & - & + & - & - & + & - \\
\hline & v & + & - & - & + & - & + & + & - \\
\hline & - & + & - & - & + & - & + & - & - \\
\hline & $\mathbf{v}$ & + & - & - & + & - & - & + & $\mathbf{v}$ \\
\hline & $\overline{\mathrm{v}}$ & $\mathrm{v}$ & - & - & $\mathbf{v}$ & - & $\mathbf{v}$ & $\mathrm{v}$ & $\begin{array}{l}\mathrm{v} \\
\mathrm{v}\end{array}$ \\
\hline & $\begin{array}{l}\mathrm{V} \\
\mathrm{v}\end{array}$ & $\begin{array}{l}+ \\
+\end{array}$ & $\bar{z}$ & $\begin{array}{l}- \\
-\end{array}$ & + & $\overline{-}$ & $\begin{array}{lll}\mathbf{v} \\
-\end{array}$ & + & $\begin{array}{l}v \\
v\end{array}$ \\
\hline & + & $\begin{array}{lll}+ \\
+\end{array}$ & $=$ & 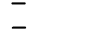 & $\begin{array}{ll}+ \\
-\end{array}$ & $\bar{z}$ & $=$ & + & + \\
\hline & $\mathrm{v}$ & + & - & - & + & - & - & t & $\mathrm{v}$ \\
\hline & - & + & - & - & + & - & + & $\mathbf{v}$ & - \\
\hline & $\mathbf{v}$ & v & - & - & + & - & $\mathbf{v}$ & - & $\mathbf{v}$ \\
\hline & $\overline{-}$ & + & - & - & $\mathbf{v}$ & - & - & + & - \\
\hline & $\mathbf{v}$ & + & - & - & t & - & - & + & - \\
\hline & - & + & - & - & + & - & + & - & + \\
\hline & - & + & - & - & + & - & v & - & + \\
\hline & $\mathbf{V}$ & + & $\bar{z}$ & - & + & - & + & - & + \\
\hline & $\mathrm{V}$ & $\begin{array}{l}+ \\
+\end{array}$ & $\bar{z}$ & $\overline{-}$ & - & - & \pm & $\overline{-}$ & \pm \\
\hline & v & + & & & - & & - & - & 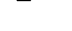 \\
\hline & $v$ & + & - & + & + & - & + & - & + \\
\hline & $\mathrm{v}$ & + & $\mathbf{v}$ & + & + & - & - & $\mathbf{v}$ & $\mathbf{v}$ \\
\hline & + & + & $z$ & $\stackrel{+}{\mathbf{y}}$ & + & - & + & - & + \\
\hline & + & $v$ & - & $v$ & + & - & $v$ & - & $v$ \\
\hline
\end{tabular}

The results of this study of 300 diverse strains of staphylococci and micrococci could be coded from the gallery but an identification from the index supplied could be made in less than $30 \%$ of trials. The three major pathogens, $S$ aureus, $S$ epidermidis and $S$ saprophyticus however, were effectively identified. Very few obvious misidentifications were seen but the micromethod was clearly not applicable to the true micrococci.

As a biotyping method the reproducibility of the individual tests becomes important as does the length of incubation. For this purpose it matters little if the micromethod gives a different result from the conventional test provided the/difference is consistent. However, if identifications are to be made from tables of standard reactions, the concordance of micromethod and conventional test results is to be desired.

The results here suggested that many of the tests performed better after $48 \mathrm{~h}$ incubation than after $24 \mathrm{~h}$. Reproducibility of the tests for acidification of maltose and mannitol and ammonia production from urea was improved and the number of discrepancies from the results of conventional tests was reduced for these substrates and for mannose and arginine. Feltham ${ }^{11}$ found greater reproducibility with the galleries he studied.

Three tests gave results that were unsatisfactory. The test for phosphatase had poor reproducibility and gave both false-positive and false-negative results when compared to the test by the method of Baird-Parker. Detection of this character has been unsatisfactory by other methods. Pennock and Huddy 15 described a tube method and claimed greater sensitivity than the method of Baird-Parker ${ }^{1}$ but we could not confirm this. ${ }^{12}$ Brun et al ${ }^{10}$ found Kloos' modification of Pennock and Huddy's method unreliable and used a modification of Baird-Parker's method. Further study of the techniques of eliciting this character are clearly required. 
For many years it has been known that the ability to split urea shows considerable variation in the rate of development of a positive test. For example, a presumptive identification of Proteus is often made on the ability of this group to alkalinise urea solutions within four hours. Staphylococcal strains vary widely in the speed of this reaction and it is therefore not surprising to find urea figuring prominently in both the late-positive and false-negative groups.

The test giving the largest number of positive results where the conventional method was negative was the production of acetoin. In the method of Baird-Parker the primary substrate is glucose in an unbuffered medium. In the micromethod the substrate is pyruvate. The difference in substrate may explain the high false-positive rate. Some biotypes have been defined on the basis of acetoin negativity by the method of Baird-Parker, so the false-positives were concentrated in these biotypes. Further work is necessary to determine whether these falsepositives were truly false.

The micromethod gallery appears to have value as an epidemiological biotyping method and for the identification by index of the three species that should be identified in all laboratories concerned with diagnostic medical microbiology. The tests included need improvement. Melibiose, raffinose, and $\alpha$ methyl glucoside were acidified very rarely and contributed little. The reproducibility and reliability of the test for phosphatase were unsatisfactory. Many tests required $48 \mathrm{~h}$ incubation but to recommend this would increase the false-positivity rate of mannose. The procedure employed here of reading the sugar reactions at 24 and $48 \mathrm{~h}$ and adding reagents at $48 \mathrm{~h}$ may be recommended.

We thank API Laboratories, La Balme les Grottes, France for donating the API Staph galleries, and Mrs J Malone for technical assistance.

\section{References}

${ }^{1}$ Baird-Parker AC. A classification of microcci and staphylococci based on physiological and biochemical tests. $J$ Gen Microbiol 1963;30:409-27.

${ }^{2}$ Baird-Parker AC. The classification of staphylococci and micrococci from world-wide sources. J Gen Microbiol
1965;38:363-87.

${ }^{3}$ Baird-Parker AC. The basis for the present classification of staphylococci and micrococci. Ann NY Acad Sci 1974; 236:7-14.

4 Pelzer K, Pulverer G, Jeljaszewicz J, Pillich J. Modification of Baird-Parker's classification system of Staphylococcus albus. Med Misrobiol Immunol 1973;158:249-57.

${ }^{5}$ Marples RR. Coagulase-negative staphylococci-their classification and problems. RSM Int Cong Symp 1980; 23:57-64.

- Kloos WE, Tornabene TG, Schleifer KH. Isolation and characterisation of micrococci from human skin including two new species: Misrococcus lylae and Micrococcus kristinae. Int J Syst Bacteriol 1974;24:79-101.

${ }^{7}$ Schleifer KH, Kloos WE. Isolation and characterisation of staphylococci from human skin. I. Int J Syst Bacteriol 1975;25:50-61.

${ }^{8}$ Kloos WE, Schleifer KH. Isolation and characterization of staphylococci from human skin. II. Int J Syst Bacteriol $1975 ; 25: 62-79$.

${ }^{9}$ Kloos WE, Schleifer KH. Simplified scheme for routine identification of human Staphylococcus species. J Clin Microbiol 1975;1:82-8.

${ }^{10}$ Brun Y, Fleurette J, Forey F. Micromethod for biochemical identification of coagulase-negative staphylococci. J Clin Microbiol 1978;8:503-8.

11 Feltham RKA. A taxonomic study of the Micrococcaceae. J Appl Basteriol 1979;47:243-54.

${ }^{12}$ Marples RR. Taxonomic studies of staphylococci and micrococci. Zentralbl Bakteriol 1981; suppl 10, 9-13.

${ }^{13}$ McKay-Ferguson E. Organic acids in microbiology. University of London MD thesis, 1977.

${ }^{14}$ Cowan ST. Cowan \& Steel's manual for the identification of medical bacteria. 2nd ed. Cambridge: Cambridge University Press, 1974.

15 Pennock CA, Huddy RB. Phosphatase reaction of coagulase-negative staphylococci and micrococci. $J$ Pathol Bacteriol 1967;93:685-7.

${ }^{16}$ Kloos WE, Schleifer KH, Noble WC. Estimation of character parameters in coagulase-negative Staphylococcus species. Zentralbl Bakteriol suppl 5, 1976;23-41.

17 Holt RJ. The pathogenic role of coagulase-negative staphylococci. Br J Dermatol 1972;86 Suppl 8:42-7.

${ }^{18}$ Mitchell RG. Classification of Staphylococcus albus strains isolated from the urinary tract. J Clin Pathol 1968;21: 93-6.

${ }^{19}$ Maskell R. Importance of coagulase-negative staphylococci as pathogens in the urinary tract. Lancet $1974 ; \mathrm{i}$ : 1155-8.

${ }^{20}$ Subcommittee on the taxonomy of staphylococci and micrococci. Minutes. Int J Syst Bacteriol 1976;26: $332-4$.

Requests for reprints to: Dr RR Marples, Central Public Health Laboratory, Division of Hospital Infection, 175 Colindale Avenue, London NW9 5HY, England. 